\title{
Inter-annual variability in cyanobacteria blooms in the Baltic Sea controlled by wintertime hydrographic conditions
}

\author{
Frank Janssen*, Thomas Neumann, Martin Schmidt \\ Baltic Sea Research Institute Warnemünde, Seestrasse 15, 18119 Rostock, Germany
}

\begin{abstract}
We investigated inter-annual variability of late summer cyanobacteria (cb) blooms in the Baltic Sea using the 3D ecosystem model ERGOM. A long-term simulation for the period 1982-1993 was carried out with realistic forcing. The simulated variability in cb blooms was in good agreement with satellite observations. Further simulations were performed in order to separate the influence of wintertime nutrient conditions from the impact of weather conditions during the growth period. There is strong evidence that the late-winter phosphate concentration in the surface layer has a determinant influence on late summer cb blooms. A large fraction of the inter-annual variability in $\mathrm{cb}$ blooms can be attributed to the variability in excess dissolved inorganic phosphorus (eDIP) in the surface layer. The amount of available eDIP in the surface layer depends on the wintertime mixedlayer depth and on the magnitude and persistency of coastal upwelling. The simulation results suggest an impact of the large-scale atmospheric conditions in winter, namely the North Atlantic Oscillation (NAO), on the occurrence of cb blooms in the Baltic Sea. It is hypothesised that the impact of the NAO is transferred by a cause-and-effect chain starting in winter and developing until late summer: high NAO index $\rightarrow$ high wind stress, low ice cover $\rightarrow$ high mixed-layer depth, strong upwelling $\rightarrow$ high surface-layer eDIP concentration $\rightarrow$ (potentially) strong cb bloom.
\end{abstract}

KEY WORDS: Cyanobacteria $\cdot$ Phosphate $\cdot$ North Atlantic Oscillation $\cdot$ Ecosystem model $\cdot$ Baltic Sea

\section{INTRODUCTION}

Late-summer blooms of diazotrophic, filamentous cyanobacteria $(\mathrm{cb})$ cause strong environmental concern both because of their potential toxicity and their fertilising effect through increased nitrogen input. cb blooms are a natural phenomenon in the Baltic Sea, and have occurred for some $7000 \mathrm{yr}$ (Bianchi et al. 2000). However, an increase in the extent and intensity of cb blooms during the last few decades is generally assumed and linked to anthropogenic eutrophication (e.g. Niemi 1979). Trends in cb biomass are, however, not easily detected, due to the pronounced patchiness and strong inter-annual variability of cb blooms, and the lack of basin-wide long-term in situ observations. Kahru et al. (1994) and Kahru (1997) quantified the inter-annual variability of the cb bloom extent during the period 1982-1994 from satellite data, and found no overall increasing trend. Instead, 2 periods with high cb concentrations were detected (1982-1984 and 1991-1994), interspersed with a period of extremely low concentrations (1985-1989).

The most important cb species in the Baltic Sea are Nodularia spumigena and Aphanizomenon sp. (Kononen 1992, HELCOM 1996). Several species of Anabaena are also present, but less common. Surface blooms are generally dominated by $N$. spumigena, but Aphanizomenon sp. often has a larger biomass. Typical summer wet-weight biomass values are about $100 \mathrm{mg} \mathrm{m}^{-3}$ for Aphanizomenon sp. and $50 \mathrm{mg} \mathrm{m}^{-3}$ for $N$. spumigena in the southern Baltic Sea (HELCOM 1996). Aphanizomenon sp. is one of the dominant nitrogen-fixers in the open Baltic Sea and is found in the upper mixed layer. The other dominating nitrogen- 
fixing species is $N$. spumigena, which generally occurs in the upper layer of the water column and often accumulates in the top few metres in the later stages of a bloom.

The nitrogen-fixing capabilities of the dominating $\mathrm{cb}$ species make them an important nitrogen source for the Baltic Sea ecosystem. Wasmund et al. (2001) calculated an annual nitrogen fixation of $370000 \mathrm{t} \mathrm{N}$. The importance of nitrogen fixation becomes obvious when this value is compared to the total riverine load of $480000 \mathrm{t} \mathrm{N} \mathrm{yr}^{-1}$ and the atmospheric load of $196000 \mathrm{t} \mathrm{N}$ $\mathrm{yr}^{-1}$ (Elmgren \& Larsson 2001).

Research on cb bloom ecology in the Baltic has identified a number of factors related to inter-annual variability of cb blooms (e.g. Niemi 1979, Kononen 1992, Sellner 1997, Wasmund 1997). The spatial distribution of one or a combination of these factors contributes to the inter-annual variability of cb blooms and thus will be briefly discussed here. The spatial distribution of $\mathrm{cb}$ in the Baltic Sea is limited to a salinity range of 3.8 to 11.5 PSU (Wasmund 1997). However, only in the transition area between the Baltic Sea and the Kattegat is variability in salinity strong enough to have a marked influence on $\mathrm{cb}$ distribution. High growth rates of $\mathrm{cb}$ are confined to water temperatures of 16 to $22^{\circ} \mathrm{C}$ (Sellner 1997) and a global radiation exceeding a daily mean of $120 \mathrm{~W} \mathrm{~m}^{-2}$ (Wasmund 1997). cb gain a competitive advantage from their ability to fix atmospheric nitrogen, with phosphorus their only limiting nutrient. A low N:P ratio is therefore often assumed favourable for cb blooms (Niemi 1979); it is generally not sufficient to trigger a bloom, but is more a prerequisite (Wasmund 1997). According to Kononen (1992), the N:P ratio is a controlling factor over a time scale of years and a spatial scale of sub-basins. However, the outcome of simulations using a numerical model for the Gulf of Finland (Kiirikki et al. 2001) indicated that the amount of available excess phosphorus rather than the $\mathrm{N}: \mathrm{P}$ ratio itself should be regarded as a controlling factor for cb blooms. In summary, we suggest that water temperature and excess phosphorus are the main factors determining the inter-annual variability of cb blooms in the Baltic Sea.

The main aim of this study was to find out which of these 2 factors has the greatest influence. Water temperature has an impact on cb blooms during the growth period, i.e. during late summer, whereas nutrient conditions of the surface layer during the growth period strongly depend on the weather conditions in winter and early spring before the onset of stratification. We can therefore distinguish between water temperature as an influencing factor with direct local temporal and spatial effects, and wintertime weather conditions with indirect effects. The wintertime weather in the Baltic Sea region is strongly coupled to the large-scale atmospheric conditions dominated by the NAO. If nutrient conditions are the dominant influencing factor for cb blooms, we can therefore postulate a strong correlation between cb blooms and the NAO.

Observational cb data are too few and too scattered to identify the dominating influence factors. We therefore chose an approach based on numerical simulations with a state-of-the-art physical-biogeochemical model. This approach allowed us a complete separation of all influencing factors and especially enabled the separation of the influence of water temperature and that of nutrient conditions on cb blooms.

\section{MATERIALS AND METHODS}

The core of the physical-biogeochemical model system we used is the ocean general circulation model MOM (Version 3, Pacanowski \& Griffies 2000, Griffies et al. 2001) adapted to the Baltic Sea. It includes an explicit free surface and an open boundary in the Skagerrak. The model grid covers the whole Baltic Sea including the Kattegat and Skagerrak, with a variable horizontal resolution ranging from $5.6 \times 5.6 \mathrm{~km}$ in the south-west to $18.7 \times 18.7 \mathrm{~km}$ in the north and east (Fig. 1). With less than $3 \mathrm{~m}$ vertical resolution down to $90 \mathrm{~m}$ depth and 77 vertical levels overall, the vertical grid spacing is adapted to resolve the thermal and haline stratification of the Baltic Sea. A thermodynamic ice model completes the physical part of the model system.

The biogeochemical part of the model consists of 9 state variables and is suited to simulate a nitrogen cycle. Dissolved ammonium, nitrate and phosphate provide the nutrients for 3 functional groups of phytoplankton: diatoms, flagellates, and cb. Diatoms represent larger cells that grow fast under nutrient-rich conditions; flagellates represent smaller cells with an advantage at lower nutrient conditions; and cb are able to fix atmospheric nitrogen and, hence, phosphate is their only limiting nutrient. Although the simulation of the Baltic Sea phytoplankton dynamics using only 3 functional groups is a strong simplification, it is adequate to represent the typical phytoplankton succession reported in the literature (Kononen 1992, HELCOM 1996). A dynamically developing zooplankton variable provides grazing pressure on the model phytoplankton, and the cycle is completed by a detritus and a sediment variable. A detailed model description can be found in Neumann (2000) and Neumann et al. (2002).

Several data sets - initialisation, boundary and forcing data - were required. The atmospheric input data, consisting of $10 \mathrm{~m}$ wind, air pressure, $2 \mathrm{~m}$ temperature, dew-point temperature, and cloud cover, were taken 


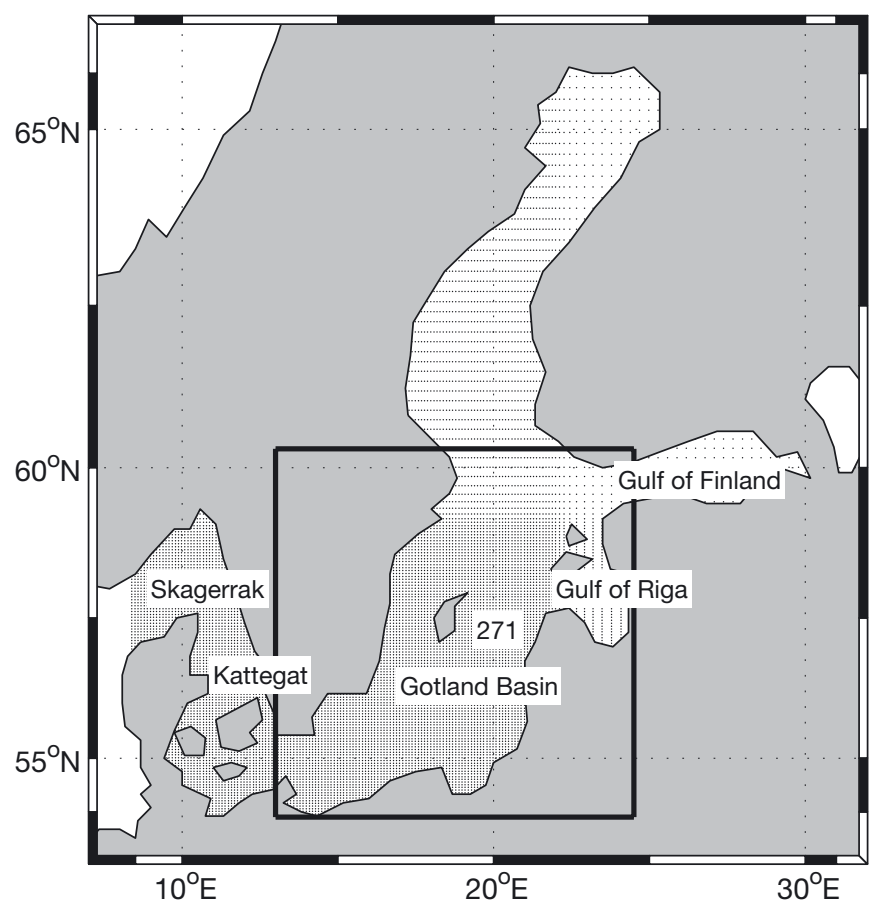

Fig. 1. Model grid. Dots indicate grid cells; investigation area is boxed. 271: monitoring station in Gotland Basin

from the first re-analysis project of the European Centre for Medium-Range Weather Forecasts (ERA-15) (Gibson et al. 1996). Data on river runoff, nutrient loads, and atmospheric deposition were provided by the Baltic Sea Environmental Database of the University of Stockholm. Initial fields as well as open-boundary values for temperature and salinity were taken from climatological data (Janssen et al. 1999). Initial data for the biogeochemical variables were taken from the model run of Neumann et al. (2002) in order to avoid a long simulation time needed to reach biogeochemical equilibrium.

\section{RESULTS}

\section{Long-term simulation}

The simulation spans the $15 \mathrm{yr}$ period 1979 to 1993. Analysis of the model results is restricted to the period and area in which the satellite observations of Kahru (1997) and the simulation overlap, i.e. the period 1982 to 1993 and area 13 to $24.5^{\circ} \mathrm{E}, 53.9$ to $60.3^{\circ} \mathrm{N}$. As a detailed description of the results from a similar simulation, including validation by observations is given in Neumann et al. (2002), the results presented here are restricted to the variables directly linked to cb blooms, with no comparison with actual observations.

Sea-surface temperature (SST) acts as a key variable for phytoplankton growth because it combines the influence of several factors, e.g. solar radiation, windinduced mixing, thermocline depth and turbidity of the surface layer. The physical conditions during the simulation period are therefore characterised by the SST averaged over the investigation area (Fig. 2). The SST shows a pronounced annual cycle, with a minimum around mid February and a maximum in early August. During the 3 very cold winters 1984/85-1986/87, the minimum temperature was near $0^{\circ} \mathrm{C}$, indicating that large parts of the Baltic Sea were covered by ice. Cold summers were simulated in 1985, 1987 and 1993. The SST anomaly in Fig. 2 indicates that the year 1987 was outstanding in that all seasons were colder than average.

Under the influence of the atmospheric forcing and the lateral boundary conditions the model reproduces the annual cycle typical for phytoplankton development in the Baltic Sea (Fig. 3b). Diatoms dominate at the beginning of the spring bloom in February/March, and are succeeded by flagellates when the nutrient concentrations start to decline (Fig. 3a). In August, the nutrients have almost reached their annual minimum concentration and nitrogen-fixing cb make up a con-

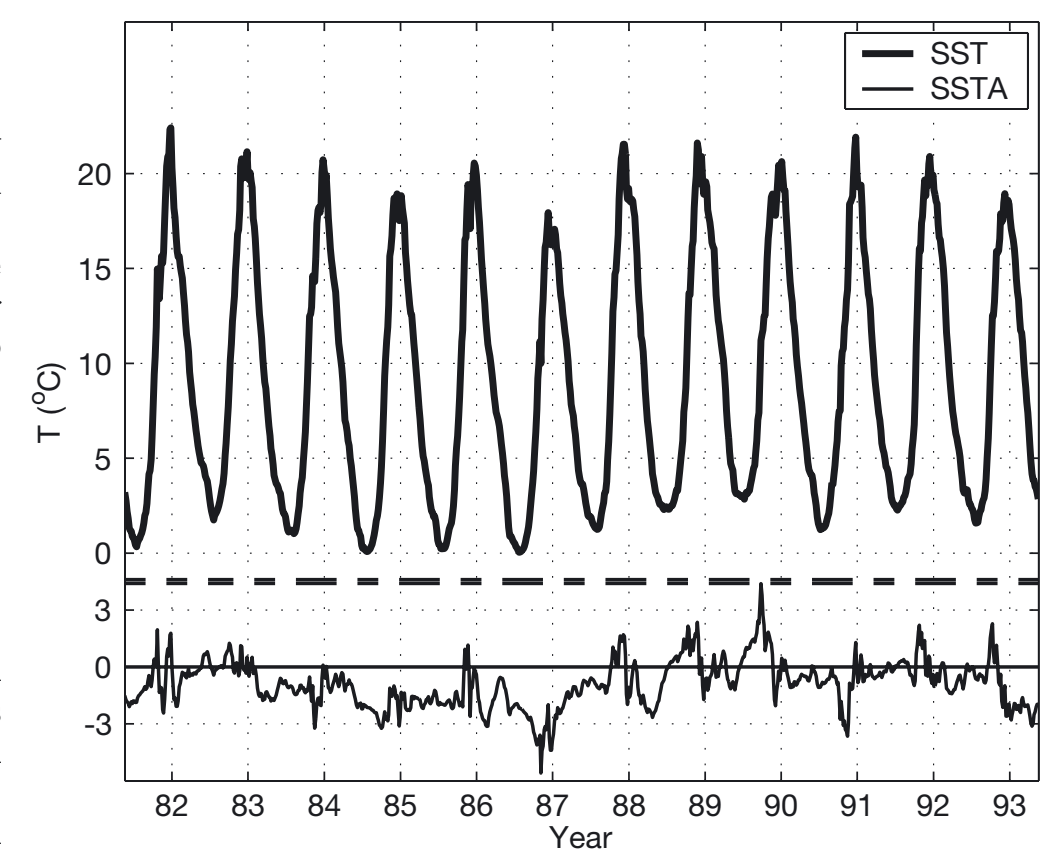

Fig. 2. Mean simulated sea-surface temperature (SST) and anomalies thereof (SSTA) from mean annual signal, 1982 to 1993. Whiskers on abscissa indicate 15 August of each year 

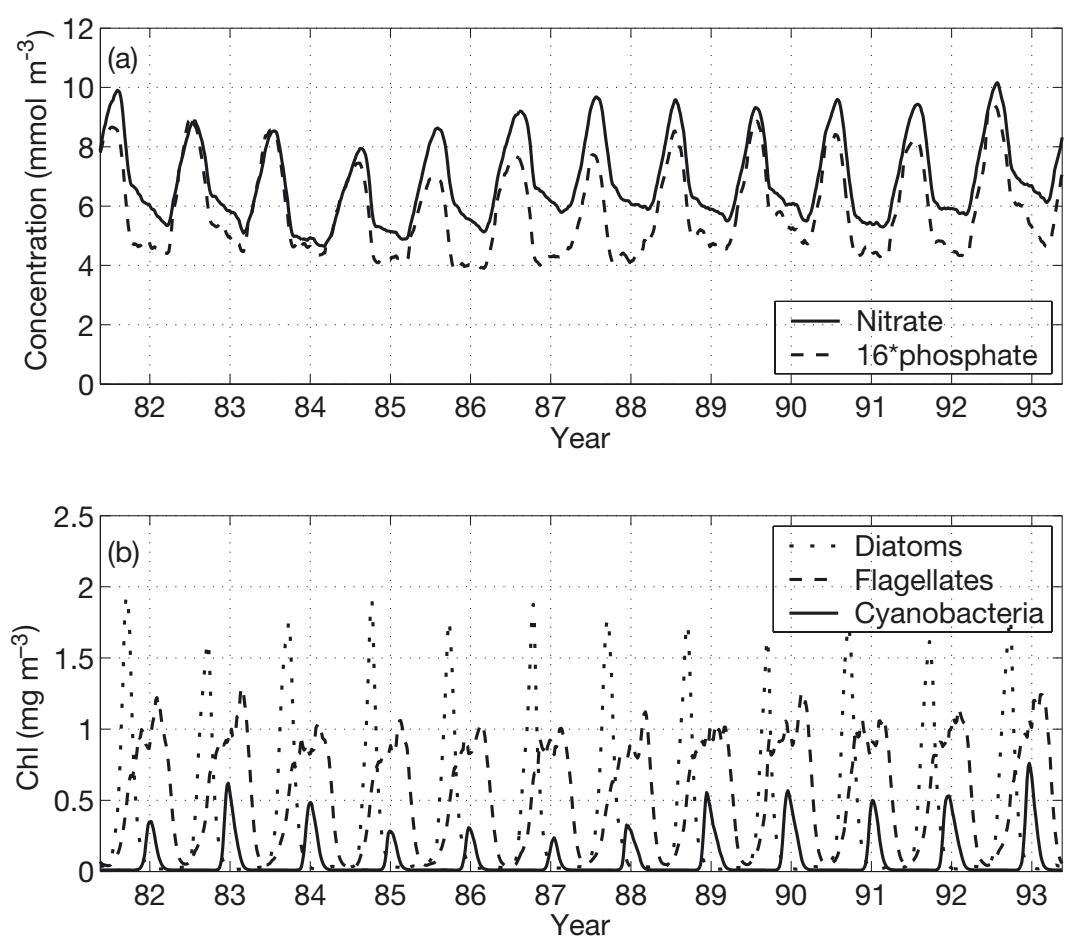

Fig. 3. Mean simulated concentrations of (a) nutrients and (b) phytoplankton in surface layer ( 0 to $40 \mathrm{~m}$ ). Whiskers on abscissa indicate 15 August of each year siderable part of the phytoplankton biomass. This phytoplankton succession is well-documented by observations (HELCOM 1996). A strong inter-annual variability in cb blooms is apparent, with low cb abundance during the years 1985 to 1988 (Fig. 3b).

The long-term mean pattern of $\mathrm{cb}$ abundance in Fig. 4a shows a pronounced east-west gradient, with very high concentrations along the Swedish coast and at the entrance to the Gulf of Finland. $\mathrm{Cb}$ are nearly absent on the east coast of the simulation area and in the Gulf of Riga. The simulated pattern is in good qualitative agree(Fig. 3.5 in Kahru 1997).

Nutrient conditions during summer are represented by the mean concentration of 'excess phosphorus' (eDIP, given in mmol $\mathrm{m}^{-3}$ ) defined as: eDIP = DIP-DIN/16 (where DIN = dissolved inorganic nitrogen). The eDIP concentration represents the amount of phosphorus remaining when all nitrogen has been consumed by the phytoplankton, under the assumption that nutrient uptake occurs at a Redfield ratio of $\mathrm{N}_{16}: \mathrm{P}_{1}$. In this study, we used eDIP concentration rather than N:P ratio to represent nutrient conditions because it includes data on the amount ment with that derived from satellite data of available nutrients and remains valid under very low nutrient conditions.

The pattern of eDIP concentration in Fig. $4 \mathrm{~b}$ bears a strong resemblance with $\mathrm{cb}$ abundance pattern, suggesting that the low $\mathrm{cb}$ abundance in the eastern part of the model area is due to phosphorus limitation. The negative eDIP concentrations in this region are due to large riverine nitrogen input from the rivers Vistula, Daugava and Odra, which cannot be utilised by phytoplankton due to the lack of phosphorus.

\section{Qualitative validation}

To validate the inter-annual variability in the simulated cb abundance in a qualitative manner, the extent of the simulated cb blooms is compared with estimates derived from satellite data (Kahru 1997) in Fig. 5. The estimates of the simulated area covered by a cb bloom are based on a threshold value of $0.2 \mathrm{mg} \mathrm{m}^{-3}$ chlorophyll. Only model grid cells with abundances exceeding the threshold value contribute to the simulated area. Obviously, the simulated area covered by cb exceeds the observed area to a large extent. Much of this discrepancy can be attributed to the different properties of observed and simulated data. Satellite data are derived by visible satellite imagery, and cb blooms are not detected until strong surface aggregations are formed, and then only under nearly cloudless conditions. Most open-water cb blooms in the Baltic are
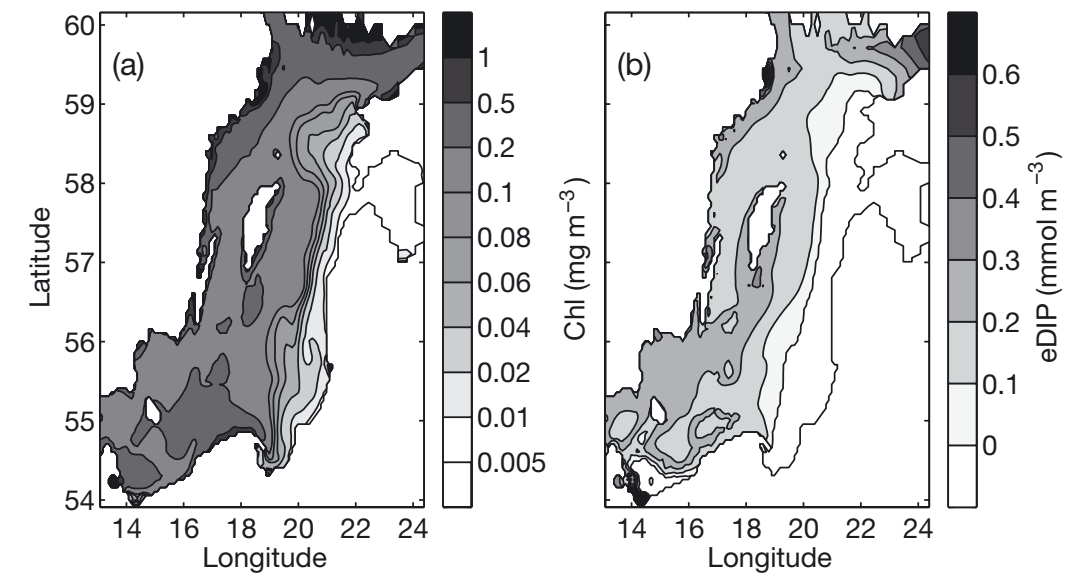

Fig. 4. Mean simulated summer (June to September) values of (a) cyanobacteria abundance and (b) eDIP concentration in surface layer (0 to $40 \mathrm{~m}$ ) 


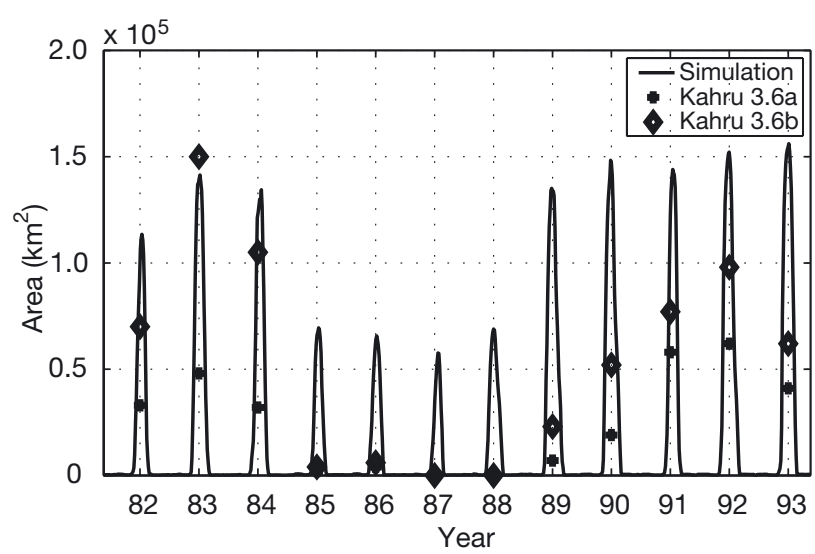

Fig. 5. Simulated and observed annual cumulative area (from Kahru 1997; his Fig. 3.6) covered by cyanobacteria blooms in Baltic Sea. Kahru 3.6a: observed series; Kahru 3.6b: series corrected for unequal number of available satellite images (for details see Kahru 1997). Whiskers on abscissa indicate 15 August of each year

composed of Aphanizomenon sp. and Nodularia spumigena, and only the latter forms satellitedetectable surface aggregations. Strong surface aggregations are formed only under calm and sunny weather conditions and at an advanced stage of the bloom. In contrast, the ERGOM model simulates $\mathrm{cb}$ concentrations throughout the water column. Although the model considers the buoyancy of $\mathrm{cb}$, it does not take into account changes in this buoyancy during the development of the bloom; hence, strong surface aggregations are not revealed by the model. Furthermore, cb abundance is simulated throughout the entire growth period, even for those periods when weather conditions are not favourable for surface aggregations. Hence, the model results are not restricted to events of surface aggregations of a single species. Consequently, the simulated area covered by cb blooms can be expected to greatly exceed estimates from satellite data. In addition to this difference in bloom magnitude, there is a striking resemblance in inter-annual variability between observed and model data. A marked drop in abundance between 1984 and 1985 separates a 3 yr period of heavy cb blooms (1982-1984) from a 4 yr period (1985-1988) of greatly reduced blooms. The observed $\mathrm{cb}$ blooms began to recover in 1989, and reached maximum in 1992; the simulated recovery was more abrupt.

\section{Quantitative validation}

A comprehensive quantitative validation of the simulated cb biomass is not possible, since the available observational data are too few and too scattered. How- ever, a few stations were sampled several times a year. Fig. 6 compares observed and simulated mean summer cb biomass at Stn 271 (see Fig. 1) in the central Gotland Basin. The simulated $\mathrm{cb}$ abundance $\left(\mathrm{mmol} \mathrm{N} \mathrm{m}^{-3}\right)$ is converted to cb biomass (wet wt), assuming a constant carbon-to-wet wt ratio of 0.11 and a Redfield ratio of $\mathrm{C}_{106}: \mathrm{N}_{16}$. Except for 1980, the model biomass reflects the observed order of magnitude. The observed interannual variability is divided into 3 distinct periods, with high values at the beginning and the end of the $15 \mathrm{yr}$ period and extremely low values in between. The model reflects this quite well, as do the satellite data (see Fig. 5). Taking into account the very low observation rate (1-5 samples a year) and the strong patchiness of cb blooms, the agreement can be considered satisfactory.

\section{Scenario simulations}

Several simulations were carried out to test the influence of atmospheric forcing (i.e. weather conditions) and model initialisation (see below) on the development of model-simulated cb blooms. Each simulation started in mid-February of the year in question and ended at the end of October, i.e. covering the annual growth period of cb in the Baltic Sea. At the beginning of each simulation, all model variables have to be initialised, i.e. all variables must be set to meaningful values at all grid points. These initial values can be estimated from observations or taken from a previous simulation. With the aim of separating the influence of weather conditions during the growth period from environmental conditions prior to the growth period, different initialisation data sets were extracted from

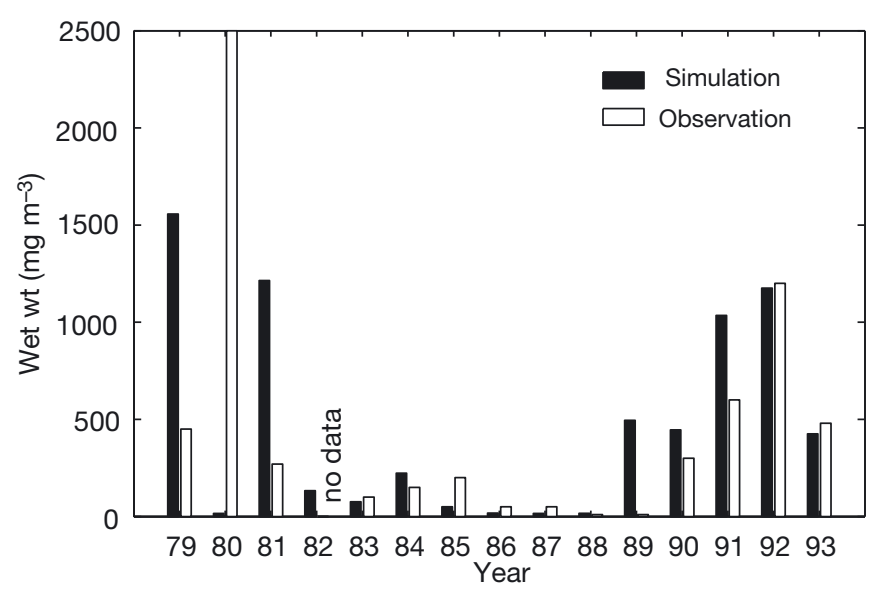

Fig. 6. Mean cyanobacteria biomass summer (June to September) in 0 to $10 \mathrm{~m}$ layer in Gotland Basin at Stn 271 (Fig. 1).

Observed data from HELCOM (1996; their Fig. 4.4.18 B) 
$1983<\mathrm{C}>=0.31$

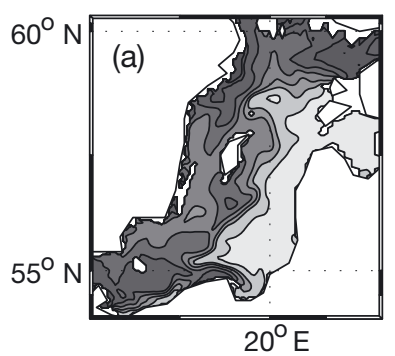

$1986<\mathrm{C}>=0.11$

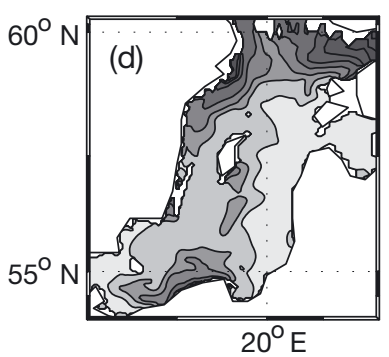

1983 ini86 $<\mathrm{C}>=0.11$
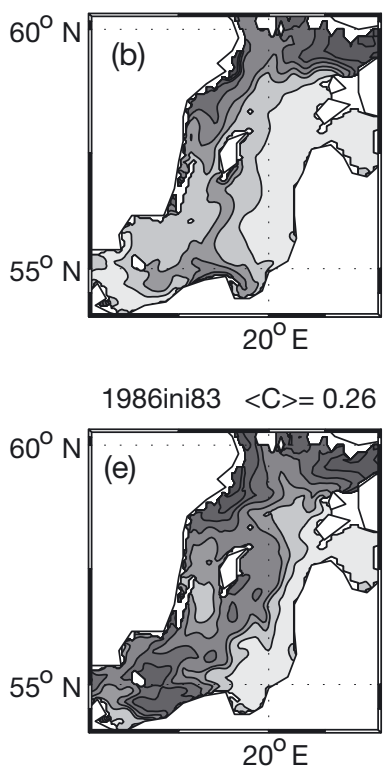

1983ini86pho83 $<\mathrm{C}>=0.41$

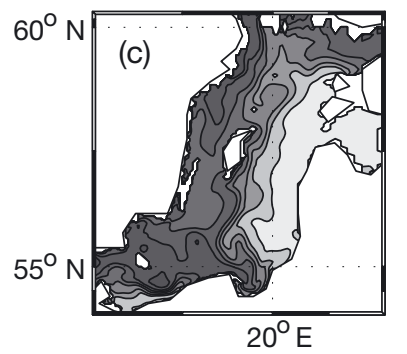

1986ini83pho86 $<\mathrm{C}>=0.16$

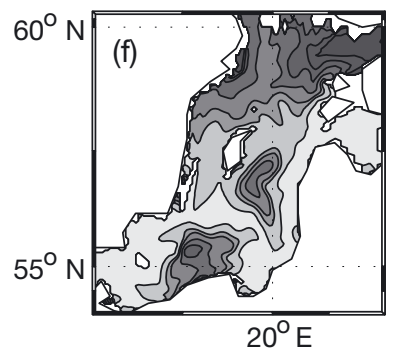

Fig. 7. Annual mean cyanobacteria abundance. Light to heavy shading indicates increasingly high concentrations. Labelling of top abscissas (from left to right): simulation year (determined by atmospheric forcing and boundary conditions); initialisation year (ini); initialisation year for phosphate (pho) if different from ini; mean annual concentration (C, $\mathrm{mg} \mathrm{m}^{-3}$ chlorophyll) with square brackets standing for the spatial mean. For further details see 'Results'

the results of the long-term simulation. We selected 2 years: 1983 (before the heavy drop in cb abundance from 1984-1985) and 1986 (after the drop). The mean annual $\mathrm{cb}$ concentration declined by $1 / 3$ from 1983-1986 (Fig. 7a-d), with the strongest decline in the southern part of the area. The model was re-run using the forcing and boundary conditions for 1983, but with the initialisation for February 1986 (Fig. 7b). Comparison of Fig. $7 \mathrm{~b}$ with Fig. $7 \mathrm{a}$ and $7 \mathrm{~d}$ reveals that annual mean $\mathrm{cb}$ abundance and distribution (Fig. 7b) bear a much stronger resemblance to the situation shown in Fig. $7 d$ than to that in Fig. $7 a$, indicating that initialisation in February is by far the dominant factor, with weather conditions during the course of the year playing a minor role. To strengthen this conclusion, the experiment was re-run using forcing and boundary conditions from 1986 and initialisation from 1983 (Fig. 7e). The mean annual cb abundance and distribution shown in Fig. 7e (i.e. 1: with forcing data from 1986 and initialisation data from 1983) are more similar to those in Fig. 7a (i.e. 2: with forcing data and initialisation data from 1983) than to those in Fig. 7d. This confirms the result of the first experiment; i.e. that initialisation, not forcing, has the strongest impact on the development of the simulated cb bloom.

These results support the hypothesis that the decline in cb abundance from 1983 to 1986 is mainly attributable to changes in environmental conditions in February, and not to differences in the weather conditions during the bloom period in these years. However, the dominating factor causing the variability in the simulated cb blooms must still be separated, as the initialisation comprises all model variables. Results of simulations with a simpler model for the Gulf of Finland (Kiirikki et al. 2001) indicate that the wintertime eDIP concentration is crucial for cb development. Therefore, 2 additional simulation experiments were carried out. In the first experiment (Fig. $7 \mathrm{c}$ ), the setup in Fig. $7 \mathrm{~b}$ was changed by using forcing and initial phosphate concentrations from 1983 and the remaining initialisation variables from 1986. This resulted in cb abundances more than 3 times higher than those in Fig. $7 \mathrm{~b}$ and even higher than those in Fig. 7a. Obviously, the February phosphate concentration had a very strong impact on cb bloom development, and it can be assumed that other initialisation factors are of minor importance. These findings are confirmed by the results of the second experiment (Fig. 7f), where the cb bloom is smaller than that in Fig. 7e but slightly higher than in Fig. 7 d.

It must be stressed that in the cases shown in Fig. $7 \mathrm{c}, \mathrm{f}$ not only the phosphate concentration itself was changed but, by keeping the nitrogen concentration constant, the N:P ratio and the eDIP concentration were also changed. In order to explain inter-annual variability in $\mathrm{cb}$ blooms the question remains as to which mechanism(s) forces the inter-annual variability of phosphate and eDIP. 


\section{DISCUSSION}

Inter-annual variability in cb blooms in the Baltic Sea revealed by satellite data has been described by Kahru et al. (1994) and Kahru (1997), but the mechanism(s) causing this variability is/are still not clear.

Atmospheric and hydrographic conditions in late summer have a clear impact on the development of $\mathrm{cb}$ blooms. Calm, sunny weather causes high SST and reduced vertical mixing, conditions favourable to large cb blooms with pronounced surface aggregations.

The influence of hydrographic conditions in winter, 6 mo ahead of the bloom on variability in the simulations is not as obvious: phytoplankton growth begins in March in the southern Baltic Sea utilising the winter nutrient concentrations. During spring and summer, diatoms and flagellates consume these nutrients at a Redfield ratio of $\mathrm{N}_{16}: \mathrm{P}_{1}$. Growth stops when one of the limiting nutrients, either phosphorus or nitrogen, is depleted (see Fig. 3). Large parts of the Baltic proper and the Gulf of Finland are nitrogen-limited, resulting in an excess of phosphorus in the surface layer in late summer (Fig. 4). This eDIP pool has the potential for blooms of nitrogen-fixing $\mathrm{cb}_{\text {; }}$ i.e. the potential of a latesummer cb bloom is determined as early as February by the eDIP concentration in the surface layer. This suggests the possibility of forecasting the potential for late-summer cb blooms from the nutrient concentrations in the surface layer before the onset of stratifica- tion in March/April. However, it assumes that deviations from the Redfield ratio in the nutrient uptake of diatoms and flagellates play a minor role. The actual strength of the bloom is naturally affected by other factors, especially by the weather conditions in summer, which determine wheter the eDIP pool is depleted or not.

A model study of Kiirikki et al. (2001) demonstrated that this causal chain is crucial to the magnitude of $\mathrm{cb}$ blooms in the Gulf of Finland. This suggests that the variability in wintertime eDIP concentrations in the surface layer is a key factor to understanding the mechanism(s) controlling the variability of cb blooms. A cause-and-effect chain of events explaining eDIP variability and its link to large-scale atmospheric conditions, i.e. the North Atlantic Oscillation (NAO), is outlined in Fig. 8.

The NAO is the dominating factor determining atmospheric variability in the northern hemisphere. It is responsible for much of the climate variability in winter in northern Europe (Hurrell et al. 2003). Comparison of Fig. 8a and 8b make this influence clear. Fig. $8 \mathrm{~b}$ shows the simulated mean winter wind-stress on the water surface, which is a result of the combined influence of the variations in wind speed and variations in ice cover strongly damping the direct momentum transfer to the ocean. Wintertime variability in both variables, surface wind and ice cover is, to a large extent, determined by the NAO (Omstedt \&
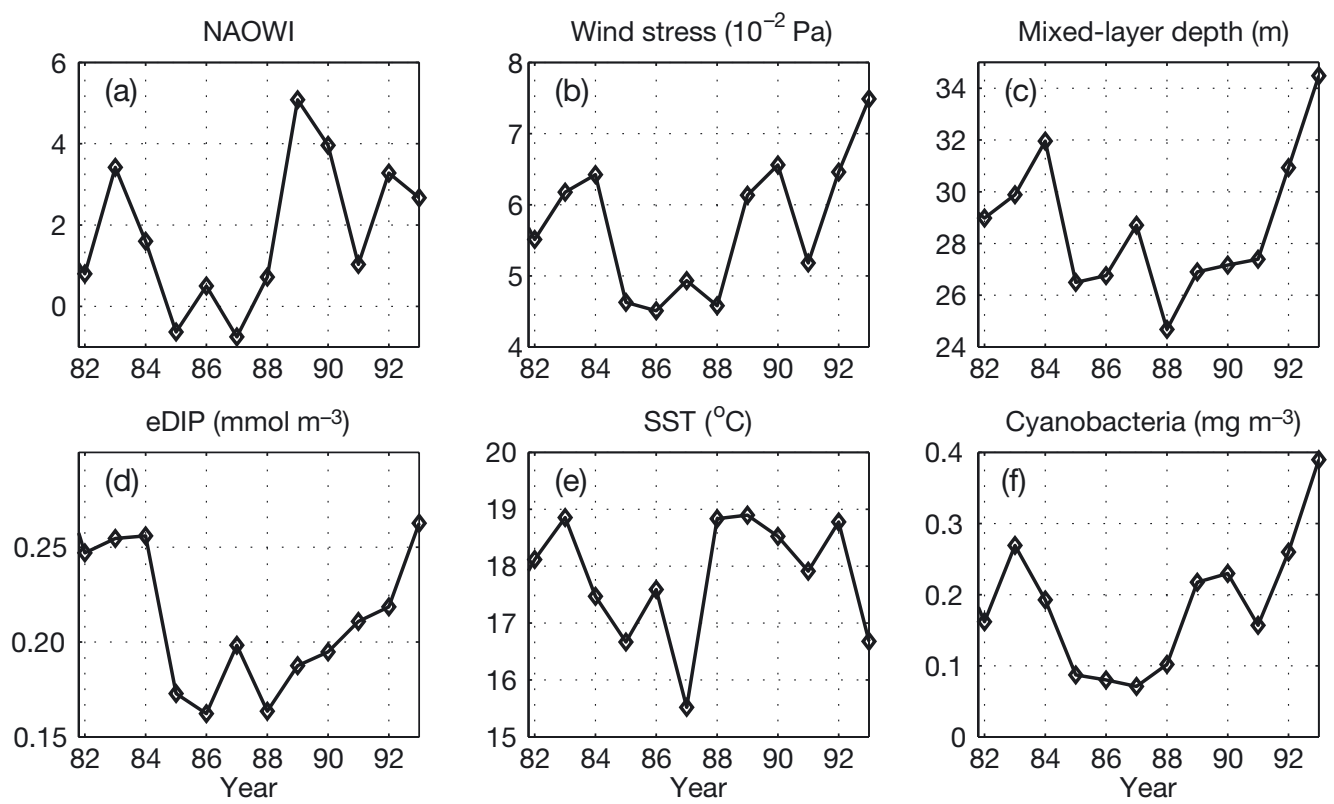

Fig. 8. Inter-annual variability in (a) North Atlantic Oscillation winter index (NAOWI) (after Hurrell 1995), (b) wind stress, (c) mixed-layer depth, (d) eDIP concentration, (e) SST and (f) cyanobacteria abundance. (b-f) Results from long-term simulation; $(c-f)$ results averaged over surface layer. Time-averaging covers different periods: (b,c) October to April, (d) January to February, $(\mathrm{e}, \mathrm{f})$ July to September 
Chen 2001). Wind stress has a strong (but not exclusive) influence on the simulated mixed-layer depth (Fig. 8c). The next element in the chain is the link between mixed layer depth and surface layer eDIP concentration manifested by the strong correlation between Fig. 8c and 8d. Prerequisites for this link are (1) a nutricline at the appropriate depth, and (2) positive eDIP concentrations below the nutricline. Both prerequisites are fulfilled in most of those parts of the Baltic Sea experiencing cb blooms (e.g. the monitoring station in the central Gotland Basin shown in Fig. 9a). Observed and simulated eDIP profiles both show a remarkable increase in concentration below about $50 \mathrm{~m}$ depth. When the mixed-layer depth reaches the nutricline, surface-layer eDIP concentrations increase by a strong upward mixing of eDIP. When the winter mixed-layer depth does not reach the nutricline, the surface layer eDIP concentrations remain at the low late-summer level of the preceding year. The number of days upon which the mixed-layer depth exceeded $50 \mathrm{~m}$ in Fig. 9b dropped sharply from 1984 to 1985. From 1985 to 1988, a depth of $50 \mathrm{~m}$ was rarely exceeded, resulting in strongly reduced upward mixing of eDIP. Although the results from a single grid point cannot be representative of the spatial mean, they are consistent with those in Fig. 8, and illustrate the suggested mechanism. Probably, the upward transport of eDIP by vertical mixing is responsible for only a part of the variability in the surface-layer eDIP concentration. A further important contribution may be made by changes in coastal upwelling and in the gyre circulation causing dynamic upwelling (Lehmann et. al 2002). The simulated eDIP variability is confirmed by an analysis of the observed phosphate concentration in the eastern Gotland Basin by Nehring (2001), whose results showed a maximum sur-
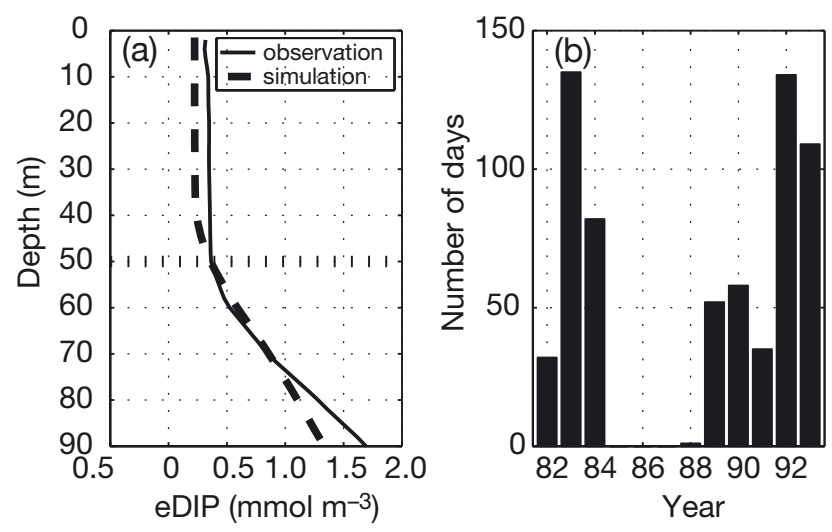

Fig. 9. (a) Mean winter (January to March) vertical profiles of observed and simulated eDIP concentrations at Monitoring Stn 271 (see Fig. 1); (b) simulated number of days when mixed-layer depth exceeded $50 \mathrm{~m}$ face-layer phosphate concentration in winter in 1984 and a strong depletion during the years 1985/86, in agreement with the simulated results in Fig. 8d.

As mentioned above, high surface-layer eDIP concentrations in winter are a prerequisite for strong latesummer cb blooms. However, high eDIP concentrations will yield strong cb blooms only if the weather conditions are favourable and the eDIP pool can be completely utilised. The limiting influence of unfavourable weather conditions was obvious in the extraordinarily cold summer of 1987 (Fig. 8e), when cb abundance remained on the low level of preceding years although the eDIP concentrations are increased markedly. Responsibility of the weather conditions for the cb concentrations below the potential limit in 1987 can be verified by a further simulation similar to that in Fig. 7e, where atmospheric forcing is taken from 1987 and initialisation from 1983. In contrast to the situation in Fig. $7 \mathrm{e}$ (where cb abundance is almost 3-fold that of (Fig. 7d), the magnitude of the cb bloom is less than doubled in 1987 when the model is initialised with data from 1983. This is a strong indication that the very unfavourable weather conditions in 1987 did not allow complete utilisation of the wintertime eDIP pool and led to a cb bloom development that was limited by weather rather than nutrient conditions.

The 2-step simulation approach summarised in Fig. 7 demonstrated that (1) the late winter environmental conditions, represented by the February initialisation data, have a major influence on the formation of $\mathrm{cb}$ blooms, and (2) model phosphate concentration is a crucial variable with respect to $\mathrm{cb}$ variability. The mechanism driving the variability in eDIP concentration is outlined in Fig. 8. It is hypothesised that the impact of the NAO on cb blooms can be described by a cause-and-effect chain starting in winter and ending in late summer. This chain has been discussed above and illustrated in Fig. 8 (summary in Fig. 10).

Fig. 10 outlines a plausible mechanism explaining much of the inter-annual variability in cb blooms in the Baltic proper during the period 1982 to 1993, but it should be borne in mind that this is only 1 of several mechanisms that can control cb variability, and that it has at least 2 restrictions.

The first restriction applies to the simulation period. The period 1979 to 1993 was the longest stagnation period in the Baltic Sea during the last century. During this period there was no inflow of North Sea water strong enough to renew the water masses in the deep basins of the Baltic Sea. Oxygen was depleted in large areas and led to high concentrations of hydrogen sulphide and a large phosphorus release from the sediments. A strong inflow of dense and oxygenated water entering the Baltic from the North Sea in January 1993 changed the situation drastically. The influence of this 


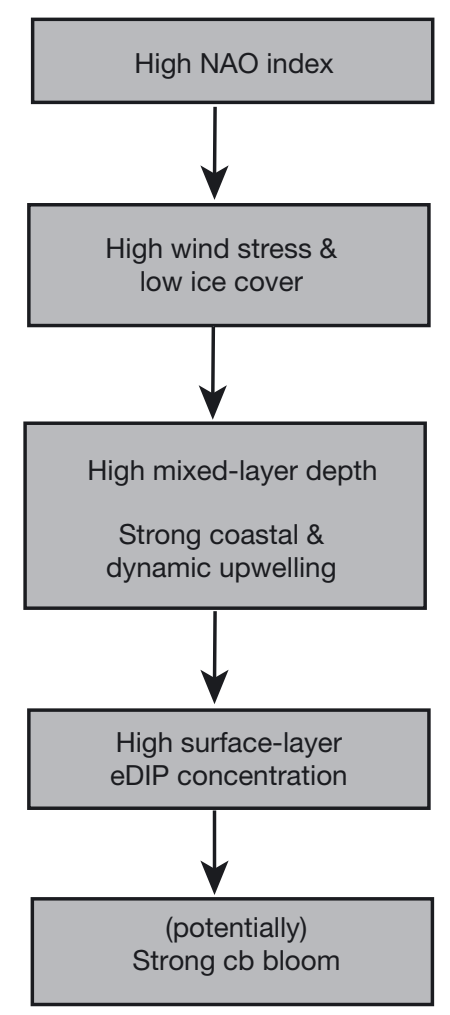

Fig. 10. Cause-and-effect chain of transfer of North Atlantic Oscillation (NAO) variability to cyanobacteria (cb) blooms in Baltic Sea

inflow on cb blooms in the Gulf of Finland was discussed by Kahru et al. (2000). Starting with the summer of 1995, strong cb blooms occurred in the central and eastern Gulf of Finland. Kahru et al. (2000) suggested changing redox conditions in the deep layers of the Gulf of Finland as a mechanism triggering $\mathrm{cb}$ blooms. Under certain circumstances, changing redox conditions can play a decisive role in the development of cb blooms.

Another restriction applies to the area under investigation. The mechanism outlined in Fig. 10 is held responsible for $\mathrm{cb}$ bloom variability in the Baltic proper. In other parts of the Baltic Sea, other mechanisms may play a larger role. For example, the situation in the Gulf of Finland is strongly influenced by frontal dynamics at the entrance to the Gulf, by coastal upwelling, and by riverine nutrient input from the River Neva.

Apart from these restrictions, the suggested mechanism should be universal. It couples ecosystem dynamics to climate variability by the influence of weather conditions in winter on nutrient conditions before the start of the growth period. This is the first documentation of the consequences of NAO-related changes in nutrient availability on phytoplankton dynamics.
Acknowledgements. The study was financed by the Federal Ministry of Education and Research (BMBF) in the frame of the IBSEN project (grant number 01LD0046) as part of the DEKLIM program. The model simulations were carried out on the super computer (HLRE) of the German Climate Computing Centre (DKRZ). We are grateful to M. Kahru, C. Schrum, P. A. Tester, and N. Wasmund for valuable comments on the manuscript.

\section{LITERATURE CITED}

Bianchi TS, Engelhaupt E, Westman P, Andren T, Rolff C, Elmgren R (2000) Cyanobacterial blooms in the Baltic Sea: natural or human-induced? Limnol Oceanogr 45:716-726

Elmgren R, Larsson U (2001) Eutrophication in the Baltic Sea area: integrated coastal management issues. In: von Bodungen B, Turner RK (eds) Science and integrated coastal management. Dahlem University Press, Berlin, p 15-35

Gibson R, Kallberg P, Uppala S (1996) The ECMWF (European Center for Medium-Range Weather Forecasts) reanalysis (ERA) project. ECMWF Newsl 73:7-17

Griffies SM, Pacanowski RC, Schmidt M, Balaji V (2001) Tracer conservation with an explicit free surface method for z-coordinate ocean models. Mon Weather Rev Am Meteorol Soc 129:1081-1098

HELCOM (Helsinki Commission) (1996) Third periodic assessment of the state of the marine environment of the Baltic Sea, 1989-1993: background document. Balt Sea Environ Proc 64B:75-104

Hurrell JW (1995) Decadal trends in the North Atlantic oscillation: regional temperatures and precipitation. Science 269:676-679

Hurrell JW, Kushnir Y, Visbeck M, Ottersen G (2003) An overview of the North Atlantic oscillation. In: Hurrell JW, Kushnir Y, Ottersen G, Visbeck M (eds) The North Atlantic Oscillation: climate significance and environmental impact. Geophys Monogr 134:1-35

Janssen F, Schrum C, Backhaus JO (1999) A climatological dataset of temperature and salinity for the North Sea and the Baltic Sea. Dtsch Hydrogr Z (Suppl 9) 245

Kahru M (1997) Using satellites to monitor large-scale environmental change: a case study of cyanobacteria blooms in the Baltic Sea. In: Kahru M, Brown CW (eds) Monitoring algal blooms: new techniques for detecting large-scale environmental change. Springer-Verlag, Berlin, p 43-61

Kahru M, Horstmann U, Rud O (1994) Increased cyanobacterial blooming in the Baltic Sea detected by satellites: natural fluctuation or ecosystem change? Ambio 23:469-472

Kahru M, Leppänen JM, Rud O, Savchuk OP (2000) Cyanobacteria blooms in the Gulf of Finland triggered by saltwater inflow into the Baltic Sea. Mar Ecol Prog Ser 207: 13-18

Kiirikki M, Inkala A, Kuosa H, Kuusisto M, Sarkkula J (2001) Evaluating the effects of nutrient load reductions on the biomass of toxic nitrogen-fixing cyanobacteria in the Gulf of Finland, the Baltic Sea. Boreal Environ Res 6:131-146

Kononen K (1992) Dynamics of the toxic cyanobacterial blooms in the Baltic Sea. Finn Mar Res 261:3-36

Lehmann A, Krauss W, Hinrichsen HH (2002) Effects of remote and local atmospheric forcing on circulation and upwelling in the Baltic Sea. Tellus 54A:299-316

Nehring D (2001) The Baltic Sea - an example of how to protect marine coastal ecosystems. Oceanologia 43:5-22

Neumann T (2000) Towards a 3-D ecosystem model of the 
Baltic Sea. J Mar Syst 25:405-419

Neumann T, Fennel W, Kremp C (2002) Experimental simulations with an ecosystem model of the Baltic Sea: a nutrient load reduction experiment. Global Biogeochem Cycles 16: $7-19$

Niemi A (1979) Blue-green algal blooms and N:P ratio in the Baltic Sea. Acta Bot Fenn 110:57-61

Omstedt A, Chen D (2001) Influence of atmospheric circulation on the maximum ice extent in the Baltic Sea. J Geophys Res C 3 106:4493-4500

Pacanowski RC, Griffies SM (2000) MOM 3.0 manual. Tech

Editorial responsibility: Otto Kinne (Editor),

Oldendorf/Luhe, Germany
Rep. Geophysical Fluid Dynamics Laboratory, Princeton, NJ Sellner KG (1997) Physiology, ecology, and toxic properties of marine cyanobacteria blooms. Limnol Oceanogr 42: 1089-1104

Wasmund N (1997) Occurrence of cyanobacterial blooms in the Baltic Sea in relation to environmental conditions. Int Rev Gesamten Hydrobiol 82:169-184

Wasmund N, Voss M, Lochte K (2001) Evidence of nitrogen fixation by non-heterocystous cyanobacteria in the Baltic Sea and re-calculation of a budget of nitrogen fixation. Mar Ecol Prog Ser 214:1-14

Submitted: October 24, 2003; Accepted: March 2, 2004 Proofs received from author(s): June 29, 2004 